\title{
ANALISIS POTENSI DAN PERSEPSI WISATAWAN DALAM IMPLEMENTASI SAPTA PESONA DI OBJEK WISATA BELERANG SIMPUR DESA KECAPI
}

\author{
Analysis Potential and Perception Tourists in Implementation of Sapta Pesona in \\ Object Belerang Simpur Tourism Kecapi Village
}

\author{
Naudita Novita Sari, Gunardi Djoko Winarno, Sugeng Prayitno Harianto, Yulia \\ Rahma Fitriana
}

Jurusan Kehutanan Fakultas Pertanian Universitas Lampung

Jl. Prof. Dr. Sumantri Brojonegoro No. 1 Bandar Lampung 35145

`Email: nauditanovitasari@gmail.com

Direvisi: 07/07/2020, Diterbitkan: 01/08/2020

\begin{abstract}
The perception of tourists is a source of information and evaluation for managers of the concept of sapta pesona that has been applied to attractions. The importance of the role of tourist can influence the management of sustainable ecotourism. This study aims to analyze the potential of tourist attractions and tourist perceptions of the implementation of sapta pesona. Determination of the sample is done by using purposive sampling. Data were collected by interview and observation techniques in the field, then analyzed descriptively qualitatively using a likert scale. The results showed that the Belerang Simpur tourist attraction consisted of three tourist attraction objects namely, Cecakhah Kenali waterfall, Belerang Simpur hot water, and natural panorama. Sapta pesona implementation based on the perception of tourists is divided into two categories, namely the category of both the elements of coolness and beauty, while the enough categories are found in the elements of security, order, cleanliness, friendliness, and memories. The development of attractions still needs to be improved by involving the role of the government and the management so that the management is more optimal.
\end{abstract}

Keywords; Tourist, sapta pesona, tourist attraction, perception

\begin{abstract}
ABSTRAK
Persepsi wisatawan merupakan sumber informasi dan evaluasi bagi pengelola terhadap konsep sapta pesona yang telah diterapkan pada objek wisata. Pentingnya peran wisatawan dapat mempengaruhi pengelolaan ekowisata berkelanjutan. Penelitian ini bertujuan untuk menganalisis potensi objek wisata dan persepsi wisatawan terhadap implementasi sapta pesona. Penentuan sampel dilakukan dengan menggunakan purposive sampling. Data dikumpulkan dengan teknik wawancara dan observasi di lapangan, kemudian dianalisis secara deskriptif kualitatif menggunakan skala likert. Hasil penelitian menunjukkan bahwa objek wisata Belerang Simpur terdiri dari tiga objek daya tarik wisata, yaitu air terjun Cecakhah Kenali, sumber air panas Belerang Simpur, dan panorama alam. Implementasi sapta pesona berdasarkan persepsi wisatawan terbagi menjadi dua kategori, yaitu kategori baik pada unsur kesejukan dan keindahan, sedangkan kategori cukup terdapat pada unsur keamanan, ketertiban, kebersihan, keramahan, dan kenangan. Pengembangan objek wisata masih perlu ditingkatkan dengan melibatkan peran pemerintah dan pihak pengelola agar pengelolaanya lebih optimal.
\end{abstract}

Kata kunci; Wisatawan, sapta pesona, objek wisata, persepsi 


\section{PENDAHULUAN}

Pengembangan objek wisata alam dipengaruhi oleh persepsi wisatawan. Hal ini disebabkan karena wisatawan dapat memberikan informasi untuk menjamin pengelolaan secara berkelanjutan (Rif'an, 2018). Persepsi wisatawan dapat dijadikan acuan yang tepat untuk mengatasi permasalahan dalam pengembangan wisata (Wisnawa et al., 2019). Apabila persepsi wisatawan rendah, maka akan menyebabkan ketidakpuasan terhadap pelayanan yang diberikan, sehingga perlu disesuaikan dengan keinginan wisatawan (Febryano dan Rusita, 2018). Salah satu strategi yang dapat dilakukan untuk memenuhi kepuasan wisatawan adalah menerapkan konsep sapta pesona pada objek wisata (Putri et al., 2020).

Sapta pesona merupakan suatu konsep sadar wisata yang diimplementasikan dengan tujuan menarik minat wisatawan untuk mengunjungi kawasan objek wisata (Hamzah dan Utomo, 2016). Unsur-unsur sapta pesona meliputi keamanan, ketertiban, kebersihan, kesejukan, keindahan, keramahan, dan kenangan (Rahmawati et al., 2017). Konsep tersebut berkaitan dengan peran dan dukungan masyarakat dalam menciptakan kondisi lingkungan yang kondusif (Wijaya et al., 2016). Selain itu, penerapan sapta pesona juga melibatkan peran stakeholder untuk mendukung keberhasilan objek wisata (Amalyah et al., 2016; Joandani et al., 2019). Rendahnya kesadaran masyarakat dan stakeholder dalam menerapkan konsep sapta pesona pada objek wisata menyebabkan pengembangan yang kurang optimal.

Pengembangan wisata alam dengan konsep sapta pesona dapat melibatkan partisipasi masyarakat lokal untuk menyediakan fasilitas kepada wisatawan (Yulianie, 2015). Keberhasilan konsep tersebut berkaitan dengan persepsi wisatawan yang berkunjung, sehingga menimbulkan kesan yang positif. Persepsi positif wisatawan memberikan dampak terhadap kunjungan kembali wisatawan. Menurut Marcelina et al. (2018), kepuasan wisatawan dapat meningkatkan jumlah kunjungan kembali wisatawan pada suatu objek wisata. Namun, kurangnya kesadaran pada penerapan sapta pesona menyebabkan pengelolaan objek wisata dinilai masih rendah berdasarkan persepsi wisatawan.

Objek wisata Belerang Simpur yang berada di hutan lindung dapat dikelola dengan menerapkan konsep sapta pesona. Septio et al. (2019) menyatakan bahwa penerapan sapta pesona mampu menjadikan lingkungan yang kondusif. Hutan lindung berfungsi sebagai daerah resapan air yang berperan dalam mempertahankan ketersediaan air dan kesuburan tanah bagi masyarakat (Panjaitan et al., 2016). Pengelolaan objek wisata di hutan lindung berfungsi untuk menjaga kelestarian sumber daya alam secara berkelanjutan yang dapat dinikmati oleh generasi di masa mendatang (Sahureka et al., 2016). Selain itu, objek wisata ini memiliki keunikan tersendiri, karena dalam satu lokasi terdapat banyak potensi yang dapat dijadikan daya tarik wisata. Tingkat penerapan sapta pesona yang belum optimal menyebabkan kurangnya minat wisatawan untuk berkunjung ke lokasi tersebut, sehingga penelitian ini menarik untuk dikaji. Tujuan dilakukannya penelitian ini adalah menganalisis potensi objek wisata dan persepsi wisatawan terhadap implementasi sapta pesona di objek wisata Belerang Simpur. Penelitain ini diharapkan dapat dijadikan landasan dalam pengembangan objek wisata.

\section{METODE}

Penelitian ini dilakukan pada bulan Desember 2019 di objek wisata Belerang Simpur Desa Kecapi, Kecamatan Kalianda, Kabupaten Lampung Selatan (Gambar 1). Objek dalam penelitian meliputi wisatawan dan potensi daya tarik wisata 


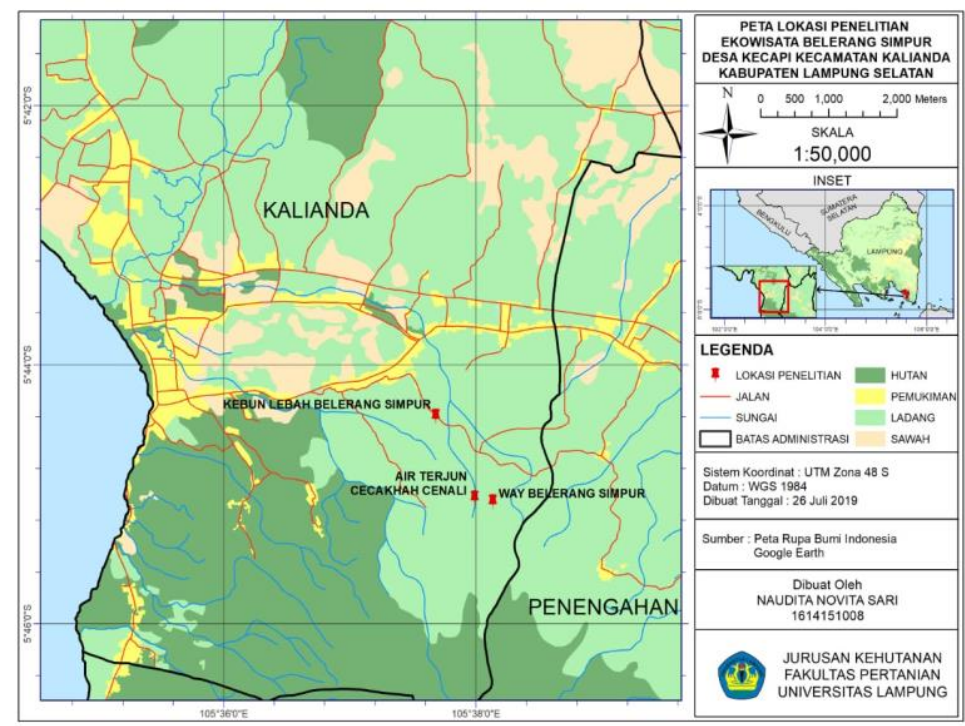

Gambar 1. Peta lokasi objek wisata Belerang Simpur Figure 1. Location map at the Belerang Simpur

Metode pengumpulan data dilakukan dengan teknik wawancara dan observasi lapangan. Teknik wawancara digunakan untuk memperoleh informasi mengenai implementasi sapta pesona di objek wisata Belerang Simpur, sedangkan observasi lapangan dilakukan dengan mencatat daya tarik potensi yang terdapat di objek wisata Belerang Simpur.

Pengambilan sampel dilakukan menggunakan teknik purposive sampling dengan rentang umur responden berkisar antara 17-60 tahun. Batasan usia tersebut, dijadikan sebagai ciri dari sampel peneliti karena memiliki tingkat berpikir yang bijak saat menjawab kuesioner yang diberikan oleh peneliti (Sahrani, 2019). Sampel ditentukan menggunakan rumus Slovin dengan presisi $10 \%$, sehingga diperoleh jumlah responden sebanyak 79 orang. Jumlah tersebut mewakili banyaknya wisatawan yang berkunjung pada lima bulan terakhir tahun 2019 yaitu 368 orang. Jika subjek yang diamati kurang dari 100 orang maka sampel diambil semua, selanjutnya jika jumlah subjeknya lebih dari 100 orang maka dapat diambil 10-15\% atau 20-25\% (Arikunto, 2014). Menurut Yustiani et al. (2017) mengungkapkan bahwa semakin besar jumlah sampel maka peluang kesalahan semakin kecil dan sebaliknya, makin kecil jumlah sampel maka makin besar tingkat kesalahan.

Analisis deskriptif dilakukan dengan mengubah bilangan skala likert ke dalam arti kualitatif masing-masing nilai scoring. Penilaian scoring pada persepsi wisatawan terhadap komponen sapta pesona terdapat lima alternatif jawaban yaitu sangat tidak baik $=1$, tidak baik $=2$, cukup $=3$, baik $=4$, dan sangat baik $=5$. Hasil scoring dikelompokkan dan diolah menggunakan teknik one score one indicator yaitu satu nilai untuk satu pertanyaan.

\section{HASIL dan PEMBAHASAN}

\section{A. Potensi Objek Wisata Belerang Simpur} berikut.

Berdasarkan hasil observasi lapangan potensi wisata di Belerang Simpur sebagai 1. Air Terjun Cecakhah Kenali

Air terjun Cecakhah Kenali merupakan objek wisata unggulan di Desa Kecapi (Gambar 2). Nama air terjun ini berasal dari bahasa Lampung, yaitu Cecakhah yang berarti air jatuh dan Kenali yang merupakan nama kebun di lokasi tersebut. Ketinggian air terjun mencapai 50 meter dan suhu air 18으.

Wisatawan memanfaatkan keindahan alam air terjun dan bebatuan yang berada di sekitarnya untuk dijadikan spot berfoto. Hal ini sejalan dengan penelitian Abidjulu (2015) yang menyatakan bahwa bebatuan di sekitar air terjun dapat digunakan sebagai objek 
pendukung dalam pengambilan gambar. Sementara itu, Yuni dan Artana (2016) mengungkapkan bahwa keberadaan air terjun dapat dinikmati oleh wisatawan hingga menimbulkan rasa nyaman dan tenang karena adanya pepohonan. Selain itu, air terjun yang berasal dari pegunungan Rajabasa dimanfaatkan wisatawan untuk berendam. Menurut Oktaviantari et al. (2019) kegiatan wisata air terjun dimanfaatkan sebagai kegiatan berendam dan menikmati guyuran air terjun.

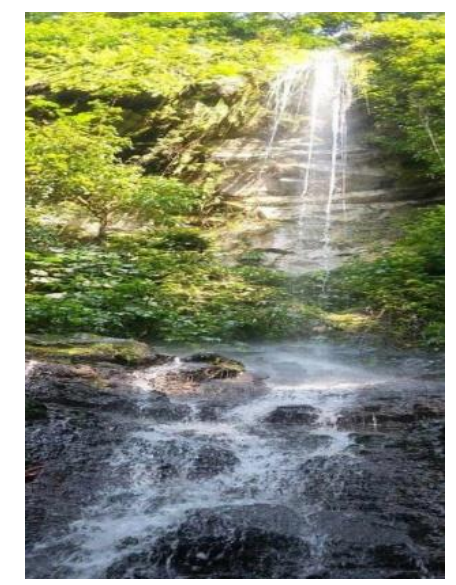

Gambar 2. Air terjun Cecakhah Kenali

Figure 2. Cecakhah Kenali waterfall

Masyarakat Desa Kecapi memanfaatkan sumber mata air terjun untuk memenuhi kebutuhan primer seperti minum, mandi, dan mencuci. Penelitian Bahtiar et al. (2015) menyebutkan bahwa air terjun dapat dimanfaatkan sebagai sistem pembangkit listrik skala kecil. Menurut Rahlem et al. (2017) air terjun memiliki fungsi ekologis yang digunakan sebagai sumber air bersih oleh masyarakat untuk memenuhi kebutuhan hidupnya.

\section{Air Panas Belerang Simpur}

Air panas Belerang Simpur memiliki luas $600 \mathrm{~m}^{2}$ dan suhu air $40^{\circ} \mathrm{C}$. Sumber mata air panas belerang berasal dari perut bumi Gunung Rajabasa di Kabupaten Lampung Selatan. Objek wisata ini mengandung gas belerang yang menimbulkan aroma menyengat seperti bau telur busuk, tetapi memiliki khasiat yang bermanfaat bagi kesehatan. Penelitian Tutu et al. (2015) menyebutkan bahwa pemandian air panas yang mengandung unsur belerang dapat menyembuhkan penyakit kulit, rematik, dan struk ringan. Wisatawan yang berkunjung ke objek wisata ini dapat berendam menikmati hangatnya air panas dan disuguhkan dengan pemandangan yang masih alami.

Objek wisata air panas Belerang Simpur memiliki keunikan yang khas berupa endapanendapan belerang yang dikelilingi oleh pepohonan (Gambar 3). Hal tersebut menjadi daya tarik bagi wisatawan untuk melakukan kunjungan kembali. Menurut Putra dan Zainuddin (2017) endapan-endapan kapur yang terbentuk dari proses panas bumi dengan kandungan belerang dapat menarik minat wisatawan. Pernyataan yang sama juga diungkapkan oleh Habib dan Rusli (2015) bahwa endapan belerang yang terbentuk secara alami memiliki eksotisme tersendiri. 


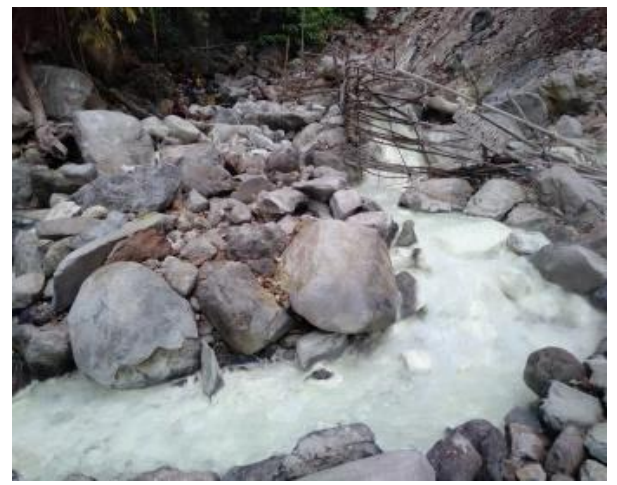

Gambar 3. Sumber mata air panas belerang Figure 3. Sulfur hot springs

Pengelola objek wisata Belerang Simpur memanfaatkan endapan-endapan belerang sebagai sabun (Gambar 4). Pembuatan sabun belerang dilakukan dengan cara mengendapkan bilah bambu di air panas selama beberapa hari hingga terisi endapan belerang. Sabun dicetak menjadi dua versi yang berukuran 200 gram dan dijual dengan harga $\mathrm{Rp} 5.000,00$, sedangkan sabun yang berukuran 600 gram dijual dengan harga $\mathrm{Rp}$ $10.000,00$. Kegiatan tersebut dapat meningkatkan perekonomian masyarakat. Hal ini selaras dengan penelitian Sugiarto et al. (2016) yang menegaskan bahwa pengolahan potensi belerang sebagai bahan baku sabun dapat menjadi peluang usaha bagi masyarakat sekitar.

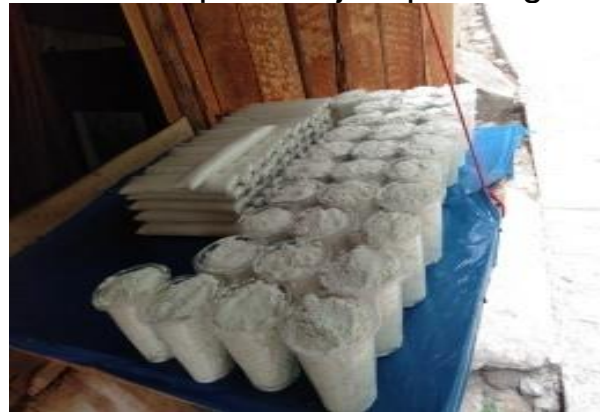

Gambar 4. Sabun belerang

Figure 4. Sulfur soap

\section{Panorama Alam}

Objek wisata Belerang Simpur memiliki posisi yang strategis karena berada di punggung Gunung Rajabasa, sehingga memberikan pemandangan alam sangat indah. Lokasi tersebut memiliki kemiringan yang curam menyebabkan wisatawan perlu hati-hati untuk menuju objek wisata. Potensi ini masih dalam rencana pengembangan untuk menambah objek wisata di Belerang Simpur. Semakin banyak potensi wisata yang dikembangkan, maka akan meningkatkan jumlah kunjungan wisatawan (Aprilia et al., 2015; Sihite et al., 2018; dan Sofiyan et al., 2019).

Pemandangan yang dapat dinikmati yaitu melihat birunya langit dan strata tajuk pepohonan yang memberikan kesan indah maupun sejuk (Gambar 5). Keanekaragaman flora dan fauna di lokasi wisata juga menjadi daya tarik bagi wisatawan. Flora yang terdapat di objek wisata yaitu pohon kecapi (Sandoricum koetjape), pohon durian (Durio zibethinus), tanaman cengkeh (Syzygium aromaticum), tanaman coklat (Theobroma cacao), tanaman kopi (Coffea canephora), dan matoa (Pometia pinnata). Fauna yang terlihat meliputi siamang (Symphalangus syndactylus), babi hutan (Sus scrafa), tupai hutan (Protoxerus stangeri), dan musang (Paradoxurus hermaphrodites). Keindahan alam dan keanekaragaman hayati dapat memberikan kontribusi dalam hal pengembangan kawasan wisata, sehingga kepuasan wisatawan terpenuhi (Murvianti dan Arida, 2015; Affandy et al., 2016; Firawan dan Suryawan, 2016; Walimbo et al., 2017; dan Pratiwi, 2019). 


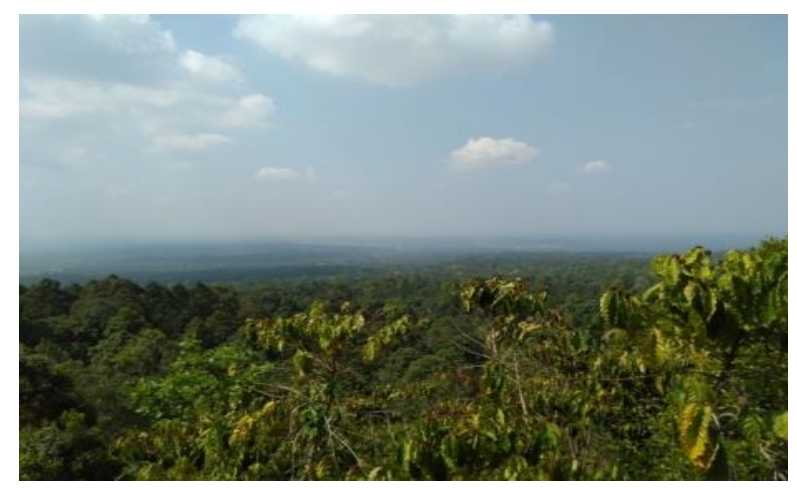

Gambar 5. Panorama alam

Figure 5. Natural panorama

\section{B. Persepsi Wisatawan terhadap Sapta Pesona}

Hasil penilaian terhadap tujuh unsur sapta pesona di objek wisata Belerang Simpur menunjukkan bahwa kesejukan memiliki nilai yang paling tinggi yaitu 4,12 termasuk ke dalam kategori baik (Gambar 6). Objek wisata ini masih alami dan dikelilingi pepohonan yang menyebabkan kondisi sekitar menjadi sejuk. Kesejukan yang ditimbulkan oleh pepohonan dapat menghubungkan perasaan seseorang secara langsung dengan alam, sehingga menciptakan rasa nyaman dan betah (Agapa dan Widyastuty, 2014; Maharani, 2014; Wanti et al., 2014; Dewi et al., 2016; dan Sulistyana et al., 2017).

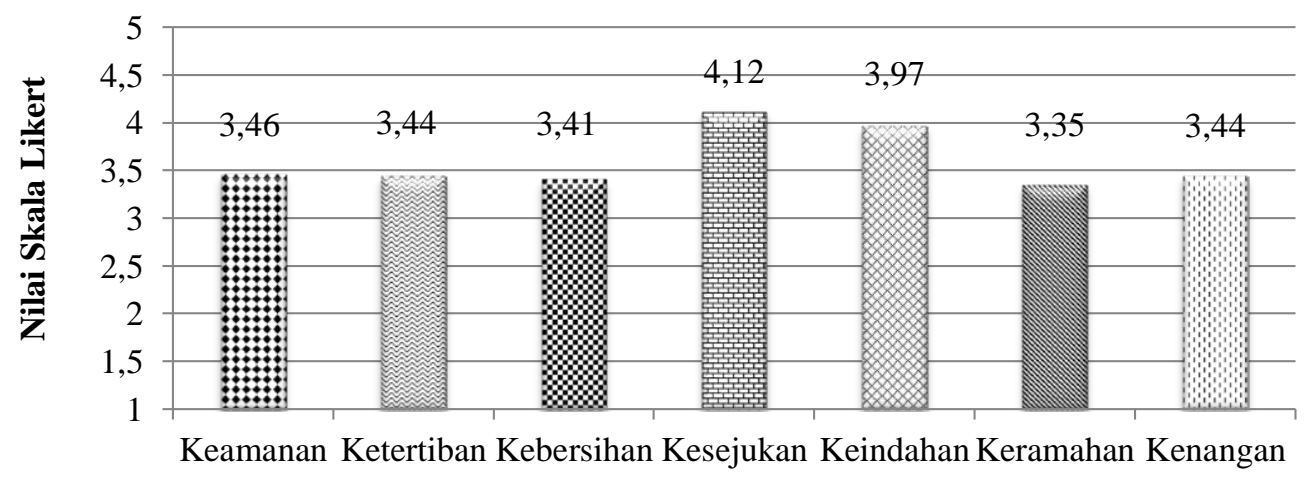

Unsur Sapta Pesona

Gambar 6. Persepsi wisatawan terhadap unsur sapta pesona Figure 6. Tourist perception of the elements of Sapta Pesona

Unsur keindahan pada objek wisata Belerang Simpur termasuk dalam kategori baik dengan nilai 3,97. Hal ini disebabkan karena objek wisata tersebut memiliki bentang alam yang dapat dinikmati oleh wisatawan, seperti air terjun, sumber air panas belerang, dan panorama alam. Menurut Ndruru dan Purba (2019), keindahan di suatu objek wisata merupakan salah satu tujuan wisatawan untuk menghilangkan kejenuhan. Suatu destinasi wisata memerlukan unsur keindahan agar memberikan kesan yang mendalam bagi wisatawan (Putri et al., 2020).

Keamanan di objek wisata Belerang Simpur tergolong cukup dengan nilai sebesar 3,46 . Menurut wisatawan objek wisata air panas kurang dijaga keamanannya karena terdapat batuan yang licin dan tidak ada pagar yang membatasi, sehingga dikhawatirkan anak-anak dapat tergelincir (Gambar 7). 


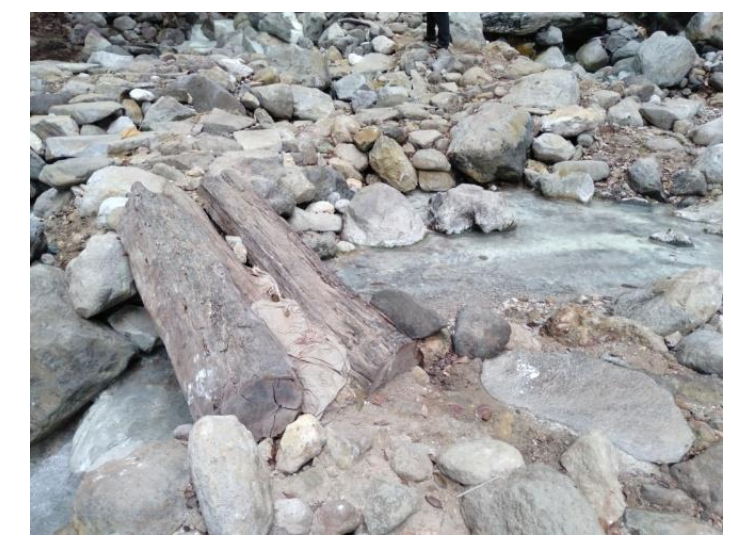

Gambar 7. Sumber mata air panas belerang yang tidak ada pagar

Figure 7. Sulfur hot springs without fences

Selain itu, belum adanya tim penyelamat juga menjadi kekurangan karena ketika terjadi sesuatu yang darurat wisatawan tidak langsung mendapatkan pertolongan pertama. Tim penyelamat merupakan pelayanan yang diperlukan untuk menanggulangi kejadian yang tidak diinginkan saat melakukan perjalanan wisata (Masrin dan Akmalia, 2019).

Ketertiban memiliki kategori cukup dengan nilai 3,44. Kurangnya ketertiban di objek wisata Belerang Simpur dapat dilihat dari petugas profesional yang belum tersedia, pelayanan yang diberikan belum maksimal, serta penataan jalan dan bangunan yang belum teratur. Selain itu, tidak adanya informasi mengenai prosedur dan tata tertib bagi wisatawan yang ingin berendam mengakibatkan wisatawan masih merasa bingung. Manuputty (2019) menyatakan bahwa terwujudnya suasana yang tertib dapat mencerminkan ketenangan dan kondisi yang teratur. Menurut Evelianti dan Heldayani (2018), pengelolaan objek wisata yang tertib dapat menimbulkan kepuasan wisatawan.

Kebersihan menjadi salah satu faktor yang mampu meningkatkan kunjungan wisatawan. Unsur kebersihan objek wisata Belerang Simpur termasuk dalam kategori cukup dengan nilai 3,41 . Hal ini disebabkan karena kamar bilas yang disediakan terlihat kumuh, sehingga sebagian wisatawan menilai lokasi tersebut kebersihannya belum terjaga (Gambar 8). Menurut Darmawan dan Fadjarajani (2016), masalah kebersihan di suatu objek wisata harus segera diatasi agar tidak menimbulkan dampak negatif bagi wisatawan. Penelitian Saputri dan Dewi (2016) mengungkapkan bahwa keadaan bersih harus selalu direalisasikan pada lingkungan objek wisata supaya mencerminkan pengelolaan yang baik.

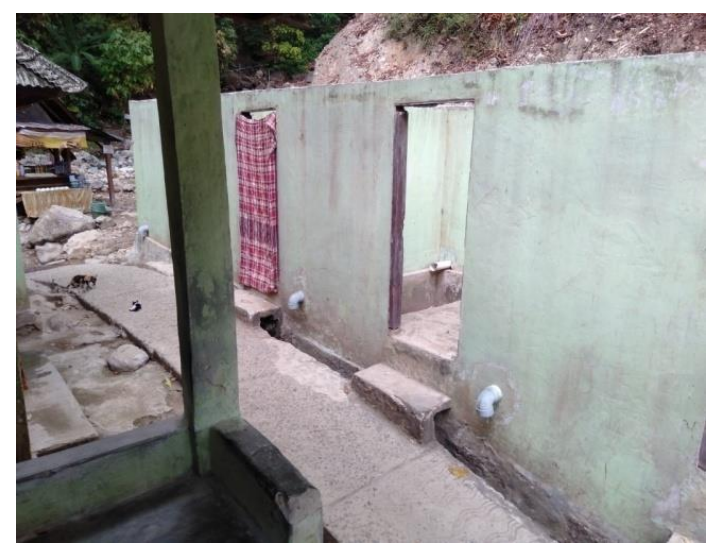

Gambar 8. Kondisi kamar bilas

Figure 8. Condition rinse room

Keramahan yang terdapat pada objek wisata Belerang Simpur memiliki kategori cukup dengan nilai 3,35 . Wisatawan beranggapan bahwa sebagian pengelola bersikap tidak peka ketika wisatawan membutuhkan sesuatu. Selain itu, sikap segan yang ditujukan pengelola menyebabkan wisatawan sungkan dalam meminta bantuan. Menurut Iswandaru et al. (2016) 
mengungkapkan bahwa komunikasi dapat menimbulkan interaksi antara pengelola dengan wisatawan. Tidak tersedianya pusat informasi menjadi suatu kendala bagi wisatawan. Menurut Evitin dan Widodo (2016), sikap yang cepat dalam memberikan tanggapan dapat menimbulkan keramahan yang menjadi salah satu faktor pendukung pengembangan objek wisata. Prawerti et al. (2015) juga menyatakan bahwa sikap pengelola yang kurang ramah terhadap wisatawan akan berdampak pada kunjungan wisatawan.

Unsur kenangan yang terdapat pada objek wisata Belerang Simpur termasuk kategori cukup dengan nilai 3,44. Tingkat kreatifitas masyarakat dan pengelola yang rendah dalam menyajikan kebudayaan lokal, makanan khas, dan cendramata menyebabkan wisatawan kurang berkesan saat mengunjungi objek wisata. Lokasi tersebut memiliki kenangan batin yang memuaskan dengan disuguhkannya keindahan alam yang tidak terlupakan oleh wisatawan. Kenangan indah dan menyenangkan akan memberikan kepuasan batin yang dapat mewujudkan getaran jiwa dan keselarasan pikiran bagi wisatawan (Agustin et al., 2014; Rakasiwi et al., 2015; dan Waani, 2016).

\section{KESIMPULAN dan SARAN}

Objek wisata Belerang Simpur memiliki tiga potensi objek dan daya tarik wisata yaitu air terjun Cecakhah Kenali, sumber air panas Belerang Simpur, dan panorama alam. Persepsi wisatawan terhadap implementasi sapta pesona terbagi menjadi dua kategori yaitu kategori baik pada unsur kesejukan dan keindahan, sedangkan kategori cukup terdapat pada unsur keamanan, ketertiban, kebersihan, keramahan, dan kenangan. Pengembangan objek wisata Belerang Simpur dapat dilakukan kerjasama dengan pemerintah untuk menunjang keberhasilan objek wisata Belerang Simpur.

\section{DAFTAR PUSTAKA}

Abidjulu, R.Z.W. 2015. Strategi pengembangan pengelolaan pariwisata air terjun Wera Saluopa di Kabupaten Poso. Jurnal Katalogis, 3(5), 1-12.

Affandy, B., Setiawan, A. \& Duryat. 2016. Potensi wisata alam di Pematang Tanggang Desa Negeri Kecamatam Kelumbayan Kabupaten Tanggamus. Jurnal Sylva Lestari, 4(1), 41-50.

Agapa, F.A. \& Widyastuty, A.A.S.A. 2014. Penataan kawasan Pulau Mansinam sebagai obyek wisata alam di Teluk Doreri Kabupaten Manokwari Propinsi Papua Barat. Jurnal Teknik WAKTU, 12(1), 8-16.

Agustin, Sentosa, S.U. \& Aimon, H. 2014. Faktor-faktor yang mempengaruhi permintaan wisatawan domestik terhadap objek wisata bahari Pulau Cingkuak Kabupaten Pesisir Selatan. Jurnal Kajian Ekonomi, 3(5), 1-20.

Amalyah, R., Hamid, D. \& Hakim, L. 2016. Peran stakeholder pariwisata dalam pengembangan Pulau Samalona sebagai destinasi wisata bahari. Jurnal Administrasi Bisnis, 37(1), 158-163.

Aprilia, F., Kumadji, S. \& Kusumawati, A. 2015. Pengaruh word of mouth terhadap minat berkunjung serta dampaknya pada keputusan berkunjung. Jurnal Administrasi Bisnis, 24(1), 1-6.

Arikunto, S. 2014. Prosedur Penelitian Suatu Pendekatan Praktik. Jakarta: Rineka Cipta.

Bahtiar, A., Hidayat, D., Minandra, J.M., Syakir, N. \& Wibawa, B.M. 2015. Aplikasi pembangkit listrik mikrohidro untuk penerangan lingkungan masyarakat di Kecamatan Ciwidey Kabupaten Bandung. Jurnal Aplikasi Ipteks untuk Masyarakat, 4(1), 15-17.

Darmawan, D. \& Fadjarajani, S. 2016. Hubungan antara pengetahuan dan sikap kelestarian lingkungan dengan perilaku wisatawan dalam menjaga kebersihan lingkungan. Jurnal Geografi, 4(1), 37-49.

Dewi, R.S., Widodo, P. \& Budiarti, L.N. 2016.Pengaruh unsur alam terhadap minat berkunjung kembali di Mal. Jurnal Visual Art dan Design, 8(2), 94-107.

Evelianti, D. \& Heldayani, E. 2018. Persepsi pengunjung terhadap sapta pesona wisata alam Gasing Water Bay Barca Banyuasin. Jurnal Swarnabhumi, 3(2), 124-129. 
Evitin, E. \& Widodo, B.S. 2016. Strategi pengembangan potensi pariwisata di Kabupaten Pacitan (studi kasus pengembangan potensi wisata Goa Gong). Jurnal Swara Bhumi, 3(3), 109-115.

Febryano, I.G. \& Rusita. 2018. Persepsi wisatawan dalam pengembangan wisata pendidikan berbasis konservasi gajah Sumatera (Elephas maximus sumatranus). Jurnal Pengelolaan Sumberdaya Alam dan Lingkungan, 8(3), 376-382.

Firawan, I.G.N.F. \& Suryawan. 2016. Potensi daya tarik wisata air terjun Nungnung sebagai daya tarik wisata alam. Jurnal Destinasi Pariwisata, 4(2), 92-95.

Habib, L.F \& Rusli, Z. 2015. Strategi pengembangan objek wisata Kawah Putih Tinggi Raja Kecamatan Silau Kahean Kabupaten Simalungun Sumatera Utara. Jurnal JOM FISIP, 2(2), 1-13.

Hamzah, F. \& Utomo, E.T. 2016. Implementasi sapta pesona pada Museum Mandala Wangsit Siliwangi Kota Bandung. Jurnal Pariwisata, 3(2), 118-128.

Iswandaru, D., Kusumandari, A. \& Fandeli, C. 2016. Studi implementasi standar sistem manajemen lingkungan (ISO 14001: 2004) dalam pengelolaan wisata alam di Taman Nasional Bromo Tengger Semeru (studi kasus pelaksanaan sertifikasi dalam pengelolaan wisata alam). Jurnal Hutan Pulau-Pulau Kecil, 1(2), 117-127.

Joandani, G.K., Pribadi, R. \& Suryono, C.A. 2019. Kajian potensi pengembangan ekowisata sebagai upaya konservasi mangrove di Desa Pasar Banggi, Kabupaten Rembang. Journal of Marine Research, 8(1), 117-126.

Maharani, D. 2014. Makna pariwisata Pulau Kemaro menurut pengunjung dan perilaku komunikasinya. Jurnal Kajian Komunikasi, 2(1), 73-83.

Manuputty, E.A.W. 2019. Penyuluhan sadar wisata di Desa Suli Kecamatan Salahutu Kabupaten Maluku Tengah. Jurnal Pengabdian Masyarakat Jamak, 2(2), 132-144.

Marcelina, S.D., Febryano, I.G., Setiawan, A. \& Yuwono, S.B. 2018. Persepsi wisatawan terhadap fasilitas wisata di Pusat Latihan Gajah Taman Nasional Way Kambas. Jurnal Belantara, 1(2), 45-53.

Masrin, I. \& Akmalia, O.K. 2019. Strategi pemasaran untuk meningkatkan kedatangan wisatawan. Jurnal Manajemen dan Bisnis Indonesia, 5(2), 204-216.

Murvianti, S.D. \& Arida, I.N.S. 2015. Potensi Pantai Perancak sebagai daya tarik wisata Desa Tibubeneng Kuta Utara Badung. Jurnal Destinasi Pariwisata, 3(2), 12-25.

Ndruru, E. \& Purba, E.V. 2019. Penerapan metode aras dalam pemilihan lokasi objek wisata yang terbaik pada Kabupaten Nias Selatan. Jurnal Manajemen Informatika dan Komputerisasi Akuntansi, 3(2), 151-159.

Oktaviantari, N.P.E., Damiati. \& Suriani, N.M. 2019. Potensi wisata alam air Terjun Kuning sebagai daya tarik wisata alam di kawasan Desa Taman Bali, Kecamatan Bangli, Kabupaten Bangli. Jurnal Bosaparis, 10(2), 136-146.

Panjaitan, U., Purwoko, A. \& Hartini, K.S. 2016. Analisis potensi dan strategi pengembangan obyek wisata alam air terjun Teroh-Teroh Desa Rumah Galuh Kecamatan Sei Bingai, Kabupaten Langkat Sumatera Utara. Jurnal Peronema Forestry Science, 5(1), 117130.

Pratiwi, N.K.O. 2019. Analisis SWOT untuk meningkatkan kunjungan wisata di objek wisata Goa Gajah Desa Bedulu, Kecamatan Blahbatuh, Kabupaten Gianyar tahun 2017. Jurnal Pendidikan Ekonomi Undiksha, 11(1), 95-105.

Prawerti, I.A.D., Mananda, S. \& Dewi, L.G.L.K. 2015. Faktor-faktor yang mempengaruhi penurunan intensitas kunjungan wisatawan di daya tarik wisata Candidasa, Kabupaten Karangasem, Bali. Jurnal IPTA, 3(1), 13-18.

Putra, K.E. \& Zainuddin. 2017. Perencanaan objek wisata alam dan tantangan dalam penyediaan infrastruktur transportasi. Jurnal Arsitektur dan Perkotaan, 8(1), 50-55.

Putri, S.A.T., Suastika, M. \& Samsudi. 2020. Penerapan konsep sapta pesona pada pengembangan Taman Budaya Jawa Tengah sebagai destinasi wisata di Surakarta. Jurnal IImiah Mahasiswa Arsitektur, 3(1), 210-219.

Rahlem, D., Yoza, D. \& Arlita, T. 2017. Persepsi pengunjung dan partisipasi masyarakat dalam pengelolaan ekowisata air terjun Aek Martua di Kabupaten Rokan Hulu. Jurnal JOM Faperta, 4(1), 1-10. 
Rahmawati, S.W., Sunarti. \& Hakim, L. 2017. Penerapan sapta pesona pada desa wisata (analisis persepsi wisatawan atas layanan penyedia jasa di kampung wisata Kungkuk, Desa Punten, Kota Batu). Jurnal Administrasi Bisnis, 50(2), 195-202.

Rakasiwi, S., Hartono, D.D. \& Muljosumarto, C. 2015. Perancangan promosi Teri Remo di Surabaya. Jurnal Adiwarna, 1(6), 1-14.

Rifan, A.A. 2018. Daya tarik wisata pantai Wediombo sebagai alternatif wisata bahari di daerah Istimewa Yogyakarta. Jurnal Geografi, 10(1), 63-73.

Sahureka, M., Lelloltery, H. \& Hitipeuw, J.C. 2016. Implementasi pengembangan ekowisata berbasis masyarakat di hutan lindung Gunung Sirimau Kota Ambon. Jurnal Hutan Pulau-Pulau Kecil, 1(2), 128-135.

Saputri, Y. \& Dewi, R.K. 2016. Penerapan program sapta pesona pada objek wisata Taman Panorama Bukittinggi. Jurnal Poli Bisnis, 8(2), 1-13.

Septio, A., Karyani, T. \& Djuwendah, E. 2019. Visitors perception about the sapta pesona implementation in Kampung Flory Sleman Yogyakarta. Journal of Business on Hospitality and Tourism, 5(2), 307-317.

Sihite, R.Y., Setiawan, A. \& Dewi, B.S. 2018. Potensi obyek wisata alam prioritas di wilayah kerja KPH Unit XIII Gunung Rajabasa, Way Pisang, Batu Serampok, Provinsi Lampung. Jurnal Sylva Lestari, 6(2), 84-93.

Sofiyan, A., Hidayat, W., Winarno, G.D. \& Harianto, S.P. 2019. Analisis daya dukung fisik, riil, dan efektif ekowisata di Pulau Pisang, Kabupaten Pesisir Barat. Jurnal Sylva Lestari, 7(2), 225-234.

Sugiarto, B., Poedjiastoeti, S., Amaria \& Muchlis. 2015. Pengolahan potensi sulfur alam sebagai komoditi industri siap jual guna membuka peluang wirausaha bagi warga kawasan ljen Bondowoso. Jurnal ABDI, 1(1), 33-39.

Sulistyana, M.I.C.D., Yuwono, S.B. \& Rusita. 2017. Kenyaman hutan kota Linara berbasis kerapatan vegetasi, iklim, mikro dan persepsi masyarakat di Kota Metro. Jurnal Sylva Lestari, 5(2), 78-87.

Tutu, R., Subaer. \& Usman. 2015. Studi analisis karakterisasi dan mikrostruktur mineral sedimen sumber air panas Sulili di Kabupaten Pinrang. Jurnal Sains dan Pendidikan Fisika, 11(2), 192-202.

Waani, H.F. 2016. Sosial budaya dalam pengembangan pariwisata di Kelurahan Bunaken Kecamatan Bunaken Kota Manado. Jurnal Acta Diurna, 5(2), 1-9.

Walimbo, R., Wulandari, C. \& Rusita. 2017. Studi daya dukung ekowisata air terjun Wiyono di Taman Hutan Raya Wan Abdul Rachman Provinsi Lampung. Jurnal Sylva Lestari, 5(1), 47-60.

Wanti, L.W., Syaukat, Y. \& Juanda B. 2014. Analisis nilai ekonomi wisata Kebun Kina Bukit Unggul Kabupaten Bandung. Jurnal Ekonomi Pertanian, Sumberdaya dan Lingkungan, 1(2), 44-55.

Wijaya, S.A., Zulkarnain. \& Sopingi. 2016. Proses belajar kelompok sadar wisata (Pokdarwis) dalam pengembangan kampoeng ekowisata. Jurnal Pendidikan Nonformal, 11(2), 88-96.

Wisnawa, I.M.B., Soharjo, S.J. \& Wijayanti, A.R. 2019. Persepsi masyarakat terhadap perilaku wisatawan Cina terhadap keberlanjutan pariwisata Bali dengan pendekatan sapta pesona. Jurnal Ekonomi dan Pariwisata, 14(1), 48-59.

Yulianie, F. 2015. Partisipasi dan pemberdayaan masyarakat dalam pengelolaan daya tarik wisata "rice terrace" Ceking, Gianyar, Bali. Jurnal Master Pariwisata, 2(1), 165-184.

Yuni, H.K. \& Artana, W.A. 2016. Strategi pengembangan air terjun Tegenungan sebagai daya tarik wisata alam di Desa Kemenuh, Gianyar Bali. Jurnal Sosial dan Humaniora, 6(3), 259-266.

Yustiani, Y.M., Emilia. \& Permana, A. 2017. Kajian valuasi ekonomi wana wisata taman hutan berdasarkan pendapat masyarakat pengunjung (studi kasus taman hutan Gunung Tangkuban Perahu). Journal of Community Based Environmental Engineering and Management, 1(1), 1-9. 